\title{
Investigation of the Process Parameters on the Blanking of AISI 304 Stainless Steel by Using Finite Element Method
}

\author{
Kaan Emre Engin ${ }^{1}$ and Omer Eyercioglu ${ }^{2}$ \\ 1. Department of Automotive Engineering, Faculty of Technology, Adiyaman University, Adiyaman 02040, Turkey \\ 2. Department of Mechanical Engineering, Faculty of Engineering, Gaziantep University, Gaziantep 27310, Turkey
}

\begin{abstract}
Blanking is a major process and has a wide range of usage in manufacturing industry. The general concept of blanking seems a simple one but governing parameters are many and have a complex relationship which directly affect the quality of the produced parts (blanks) and also the energy efficiency of the process. The main problem is the lack of prediction capabilities of the effect of these parameters that lead to time, money and labor consuming trial and error procedures in experimental studies. Usage of FEM based programs to simulate blanking to obtain numerical results and observe the shearing mechanism is a cheap and a detailed way for industrial applications. In this study five different clearances $(1 \%, 3 \%, 5 \%, 10 \%$ and $20 \%)$ and three different thicknesses $(t=2 \mathrm{~mm}, t$ $=3 \mathrm{~mm}$ and $t=4 \mathrm{~mm}$ ) were used for simulation and experimental studies of the blanking process. Simulations were executed by using the FEM program, Deform 2-D. Investigations were made on the parameters related to crack progression like crack initiation and crack propagation angles, indentation angle, rollover angle and depth and also the related blanking energy values. The results of the present paper are in agreement with the results of experimental studies.
\end{abstract}

Key words: Blanking process, sheet metal, process parameters, shearing mechanisms.

\section{Introduction}

Blanking is one of the most important processes in sheet metal processing industry and has many parameters that have to be considered to achieve required blank quality. Because as in every production cycle, blanking process has a downside which is; generally, a subsequent deburring is required. This need of cleaning operations causes an increase in the processing time and labor costs. If the burr formation can be eliminated by proper adjustments on blanking parameters, there may be a decrease in final finishing processes hence the cost. The overall goal is to improve the blanked parts surface quality in such a way that the produced part does not need to be reworked.

The main working principle of blanking seems quite simple; a workpiece (strip) is placed between a

Corresponding author: Kaan Emre Engin, Res. Asst., M.Sc., research fields: blanking, press systems. predetermined shaped upper die (punch) and a same shaped lower die. Then with the downward movement, the punch plunges into the lower die while shearing the workpiece into that predetermined shape. The sheared part becomes the blank while the remaining strip becomes the skeleton. Although these steps of the process seem simple, achieving a good surface quality on the blank relies on many parameters. Clearance which is the relative space between the punch and the lower die and is the most effective parameter, material type of the workpiece and thickness, shape of the component, tool geometry and many other parameters are directly in conjunction with each other [1]. Also energy efficiency is a major concern and spending of the energy should be low while executing blanking. In other words, all parameters should be in alignment with each other to create the ideal blanking condition which the blank quality is best and spent energy is lowest. These are the reasons that make blanking a complex 
and a difficult process to predict. This lack of prediction leads to time, money, energy and labor consuming trial and error procedures, especially for experimental studies.

As an alternative approach, usage of FEM based programs to simulate blanking for obtaining numerical results and observing the shearing mechanism is a cheap and a detailed way for industrial applications.

Despite the studies using experimental methods, researchers have been trying to model the blanking process by using FEM approaches for many years. Some models tried to assess the parameters like; clearance, friction and mesh adaptivity $[2,3]$. But the lacking side of these studies were; they didn't consider the sheared edge formation on the blank which is highly necessary to be predicted. In order to improve this gap, new approaches have been developed. Faura et al [4], tried to determine optimum clearance by presenting crack propagation angles throughout the sheared edge. Hambli et al, studied the same concept and also integrated neural networks to predict burr heights and to optimize the blanking process [5-7]. Both researchers claimed that optimal clearance for the given material is around $10 \%-12 \%$ as a result of their FEM algorithm. But those values of optimal clearance are quite high to achieve a good surface quality. Prediction of burr formation [8-10] and sheared edge quality [11-13] in blanking have been investigated also by other researchers. They used different programs and behavior laws to predict the ductile fracture phenomenon in blanking. As a result, the general acceptance is that if a good surface quality is desired, clearance value has to be $5 \%$, if low blanking forces are desired, clearance has to be at least $10 \%$ and above. Hereby, they stated that it's up to the practitioner's choice between quality and energy efficiency.

In this study, to observe the claims stated by previous researchers; five different clearances $(1 \%, 3 \%$, $5 \%, 10 \%$ and $20 \%)$ and three different thicknesses $(t$ : $2 \mathrm{~mm}, t: 3 \mathrm{~mm}$ and $t: 4 \mathrm{~mm}$ ) were used for both simulative and experimental study. Simulations were executed by using the FEM program; Deform 2-D. Experimental studies were executed by using a hydraulic press and a manufactured die system. The concept of indentation angle, rollover angle and their relation with other parameters were introduced. Investigations were also made on rollover depth, crack initiation and crack propagation angles. Also blanking energy distribution for these clearances and thicknesses were examined.

\section{Process Parameters}

\subsection{Ideal Cutting Condition}

The ideal cutting condition is where the punch energy is the lowest for energy conservation and the quality of the blanked part is so good that no extra labor is needed to correct the defects on the blanked part surfaces.

When a material is blanked, deformation happens in a narrow zone called the shear band. Good surface quality depends on the deformation path of the shear band which is directly affected by the clearance. In blanking process, clearance (c) is taken as a percentage of the sheet thickness and defined by;

$$
c: \frac{100\left(D_{m}-D_{p}\right)}{2 t}(\%)
$$

where, $D_{m}$ is the lower die diameter, and $D_{p}$ is the punch diameter and $t$ is the thickness of the strip material.

The ideal cutting condition is achieved when the angle $(\beta)$ which is the angle of real crack propagation direction and angle $(\theta)$ which is the angle of ideal crack propagation direction coincides with each other. If this condition can be procured, the blanked part has burr free surfaces. If the crack propagations don't coincide, secondary crack formation occurs that creates lower surface quality. The directions of angle $(\beta)$ and angle $(\theta)$ were illustrated in Fig. 1. As can be seen, real crack propagation direction doesn't coincide with the ideal crack propagation direction, creating secondary cracks. The equalization of ideal crack propagation angle $(\theta)$ and the angle of the direction of crack propagation $(\beta)$ giving the ideal cutting condition can be expressed as: 


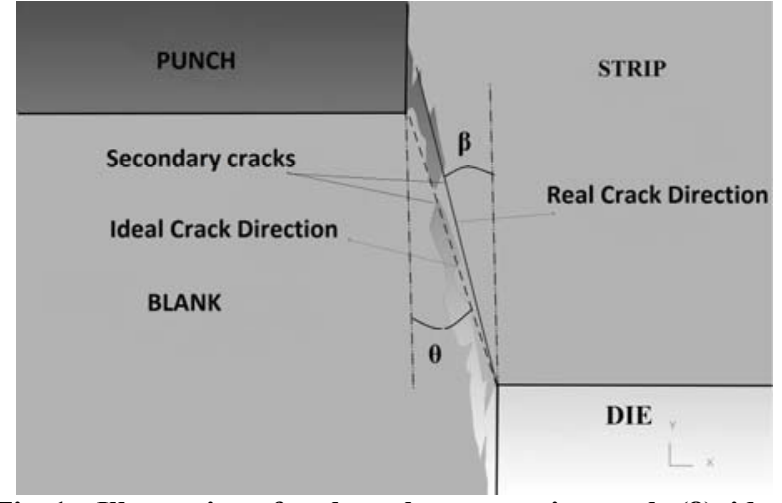

Fig. 1 Illustration of real crack propagation angle $(\beta)$, ideal crack propagation angle $(\theta)$ and secondary cracks.

$$
\Phi=\beta-\theta \cong 0
$$

The ideal crack propagation angle can be expressed by;

$$
\theta=\operatorname{Arctan}\left(\frac{c}{t-u_{p}}\right)
$$

where, $c$ is the clearance; $t$ is the workpiece (strip) thickness and $u_{p}$ is the punch penetration corresponding to the first crack initiation within the sheet.

\subsection{Indentation Angle. Rollover Angle and Depth}

During the penetration of the punch, material is subjected to bending that creates indentation angle $(\alpha)$ on the upper portion of the blank.

Also, while punch penetrates into the workpiece, material is pulled down into the clearance space which creates rollover. Rollover depth $\left(\mathrm{R}_{\mathrm{d}}\right)$ is calculated from the lower side of the workpiece to the indentation ending. Rollover angle $\left(\mathrm{R}_{\mathrm{a}}\right)$ is the angle between the lowest bottom of the workpiece and rollover depth end point. Illustrations of these parameters were given in Fig. 2.

\subsection{Finite Element Model}

Drawing of the FEM models and execution of simulations were done on a $2 \mathrm{D}$ plane by using Deform-2D. The FEM model was considered axisymmetric, so only one half of the tooling was modelled for executing the runs. The blanking setup considered for simulations had four components: the

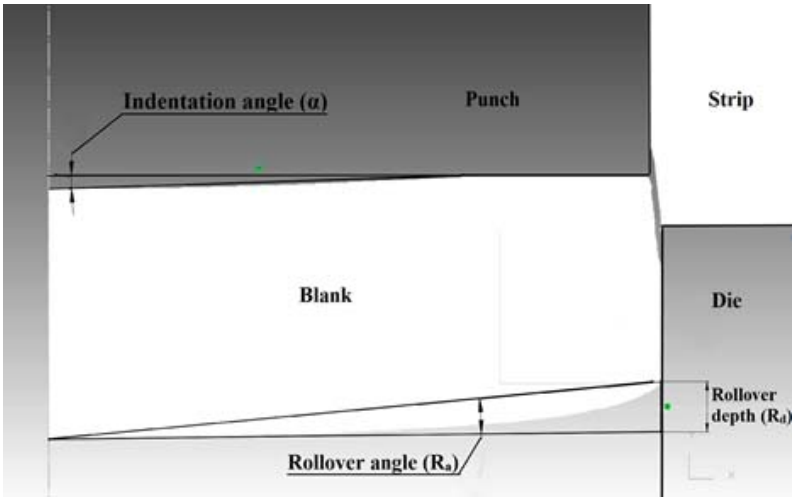

Fig. 2 Illustration of indentation angle $(\alpha)$, rollover depth $\left(R_{d}\right)$ and rollover angle $\left(R_{a}\right)$.

punch, lower die, sheet material and a blank holder to prevent bending of the strip. The punch, lower die and blank holder were assumed to be non-deformable. So, the sheet material was considered as a plastic object whereas the punch, die and blank holder were considered as rigid bodies. Also no radiuses were given to the corners of the punch and lower die.

Fracture criterion has an utmost importance in the simulation of blanking to gather realistic results. Because of its accurate prediction capabilities of the fracture strain, the fracture criterion was chosen Normalized Cockroft and Latham. The criterion states that the fracture occurs when the effective strain reaches the critical value expressed as;

$$
\int_{0}^{\varepsilon^{-t}}\left(\frac{\sigma^{*}}{\bar{\sigma}}\right) d \bar{\varepsilon}=C
$$

where, $\sigma^{*}$ is the maximum principal tensile stress, $\varepsilon^{-f}$ the fracture strain, and $C$ is the critical value. The effective stress and effective strain are defined as $\bar{\sigma}$ and $\bar{\varepsilon}$.

As mentioned before, during the blanking process, shearing of the workpiece happens in a narrow zone called the shear band. The stress ratio $\left(\frac{\sigma^{*}}{\bar{\sigma}}\right)$ is assumed to be constant throughout that band where the deformation is highly concentrated. Therefore this assumption may be implemented into Cockroft and Latham criterion and approximated by $\varepsilon^{-f}=C^{*}$ at 
the shear band. This approach postulates that a crack initiation occurs at the point of the sheet whose effective strain first reaches the fracture strain of the work material [4]. The program uses element deletion method to iterate the meshing procedure and deletes an element when the critical values are satisfied. But every time program stops and performs element deletion, a small part from the blank has gone missing that leads to volume degradations and miscalculations. To prevent and limit this situation, a very fine has to be defined in the FEM model. To achieve a very dense mesh, 10000 isoparametric quadratic elements were used as the element meshes of the workpiece. Further, mesh elements were concentrated around the deformation zone by using mesh density windows that move with the punch and try to hold the mesh density in its specific intensity during re-meshing. The geometrical model of the blanking process and the FEM meshes of the workpiece can be seen in Fig. 3 .

\subsection{Experimental Setup}

The isometric view of the designed die and its components were given in Fig. 4. The die consists of six components; upper die block (1), punch holder (2), punch (3), fixed stripper (4), lower die (5) and lower die block (6).

The upper die block, punch holder, fixed stripper and lower die block were made of St 37 steel whereas the guide rods on the upper die block, punch and lower die were made of heat treated AISI 4140 for long durability.

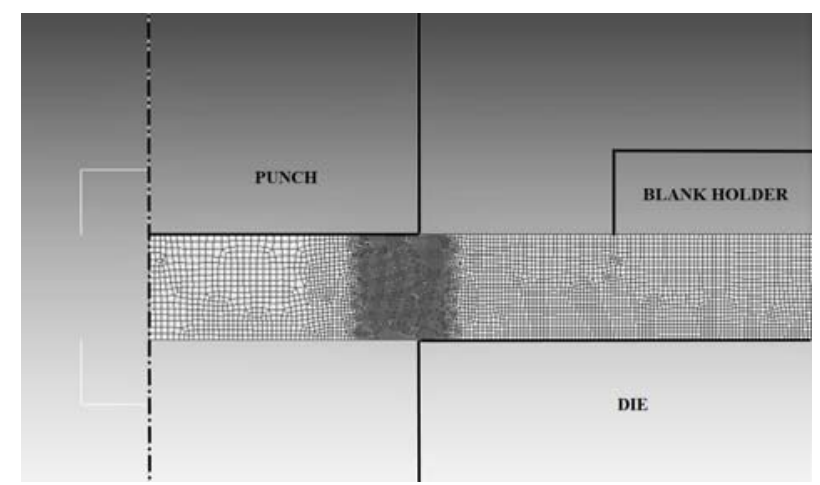

Fig. 3 The finite element model of the blanking process and the meshes of the workpiece.

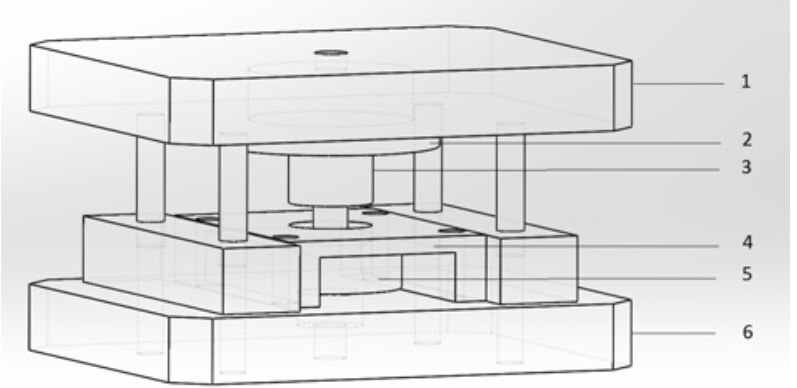

Fig. 4 The isometric view of the die assembly.

All experiments were made by a hydraulic press which had adjustable speed and loading capabilities.

\subsection{Material Model and Experimental Parameters}

AISI 304 stainless steel was used for both simulation and experimental studies. AISI 304 is a very common type of stainless steel used in different kinds of industrial applications. AISI 304's usage areas can vary from simple hypodermic needles to moderate applications like marine industry and heavy industry zones like nuclear plants [14].

Mechanical properties of AISI 304 were given in Table 1.

Sheet thickness was taken as $t=2 \mathrm{~mm}, t=3 \mathrm{~mm}$ and $t=4 \mathrm{~mm}$. Lower die diameter was taken $10 \mathrm{~mm}$ and clearances as $1 \%, 3 \%, 5 \%, 10 \%$ and $20 \%$ for all experiments. Velocity and loading had been kept constant for all simulations and 30 tons at constant speed of $0.01 \mathrm{~m} / \mathrm{s}$ were used to execute the blanking processes.

\section{Results and Discussion}

The microscopic image of a blanked part and the image taken from Deform program were given in Fig. 5.

Table 1 Mechanical properties of AISI 304.

\begin{tabular}{ll}
\hline Property & Value \\
\hline Tensile Strength, Ultimate & $505 \mathrm{MPa}$ \\
Tensile Strength, Yield & $215 \mathrm{MPa}$ \\
Elongation at Break & $70 \%$ \\
Modulus of Elasticity & $193-200 \mathrm{GPa}$ \\
Poisson's Ratio & 0.29 \\
Charpy Impact & $325 \mathrm{~J}$ \\
Shear Modulus & $86 \mathrm{GPa}$ \\
\hline
\end{tabular}




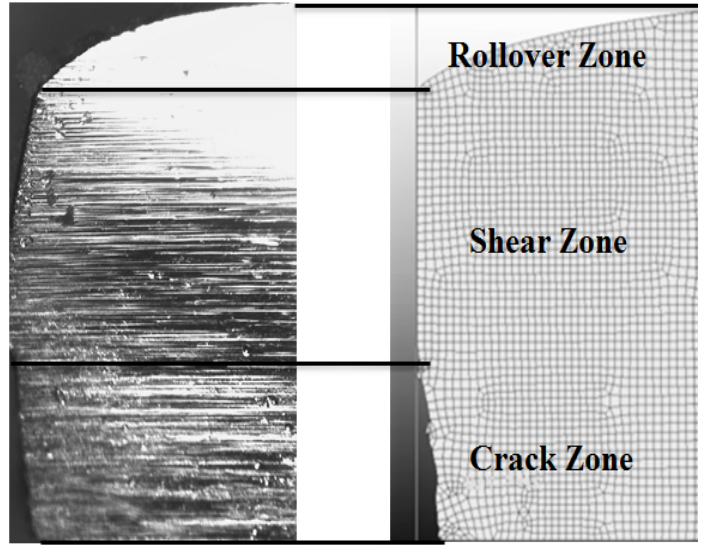

Fig. 5 The microscopic and the simulation images of a blanked part $(t=2 \mathrm{~mm}$, clearance: $5 \%)$.

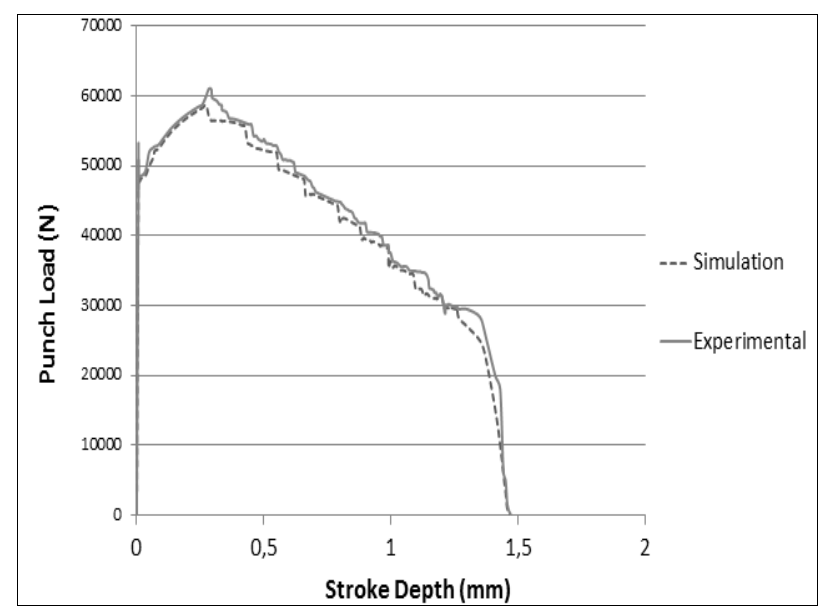

Fig. 6 Change in punch load for simulation and experimental results $(t=2 \mathrm{~mm}$, clearance: $5 \%)$.

As can be seen that crack propagations and related zones are similar between experimental and simulation results. The numerical values gathered from experiments and simulations (Punch load, stroke, blanking energy, etc.) are also similar. Punch load difference between simulation and real experimental values were given in Fig. 6.

\subsection{Blanking Energy}

Energy saving is a major concern in every process. But in blanking, the situation hangs in a balance between surface quality and energy. Many theoretical and experimental studies showed that an increase in clearance results as a decrease in the blanking load [2, 9, $15,16]$. But this implication may lead to wrong interpretation of the results. Because taking punch load

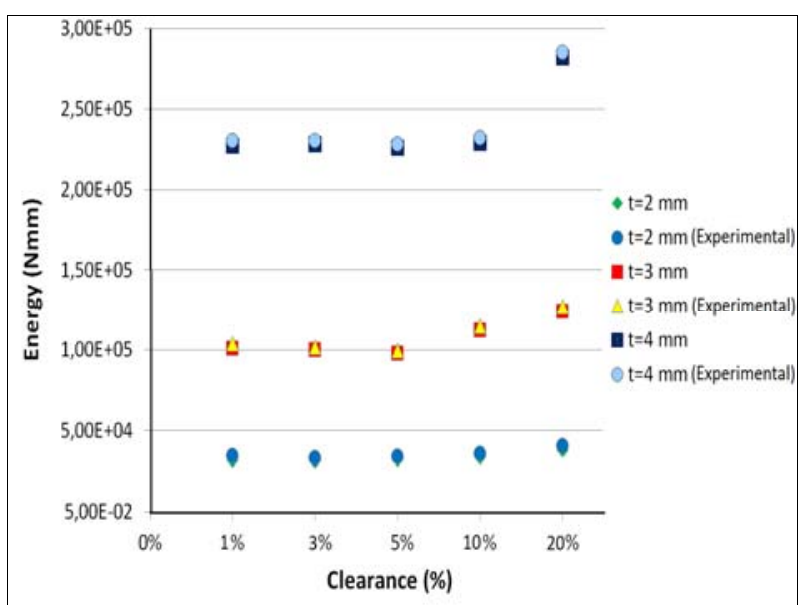

Fig. 7 The blanking energy with respect to clearance from the results of simulations and the experiments.

as the ultimate energy saving parameter is wrong due to the changing stroke depth according to the clearance. Instead, taking blanking energy which is the ratio between punch load and stroke depth gives much more realistic insight to the situation. Blanking energy difference between simulation and experimental values were given in Fig. 7.

Fig. 7 shows that lowest blanking energies were achieved at $3 \%$ clearance for $t=2 \mathrm{~mm}$ and $5 \%$ for $t=3$ $\mathrm{mm}$ and $t=4 \mathrm{~mm}$. Also blanking energy rises for all thicknesses when the clearance exceeds $10 \%$. With these results, it is not a right decision to accept the concept of giving higher clearance to increase energy efficiency by decreasing punch load. Also expecting good surface quality with a high clearance is unlikely.

\subsection{Crack Propagation Angles}

The difference between real crack propagation angle $(\beta)$ and ideal crack propagation angle $(\theta)$ was calculated according to $\Phi=\beta-\theta$ condition. The condition postulates that the closer $\Phi$ to zero, cleaner the blanked surface. The differences $(\Phi)$ according to clearances for $t=2 \mathrm{~mm}, t=3 \mathrm{~mm}$ and $t=4 \mathrm{~mm}$ were given in Fig. 8. The results showed that workpiece thickness had an effect on crack propagation. The closer values to zero were found when the clearance was $3 \%$ for $t=2 \mathrm{~mm}$ and $5 \%$ for $t=3 \mathrm{~mm}$ and $t=4 \mathrm{~mm}$. Also, as the clearance increased, the difference between real crack 


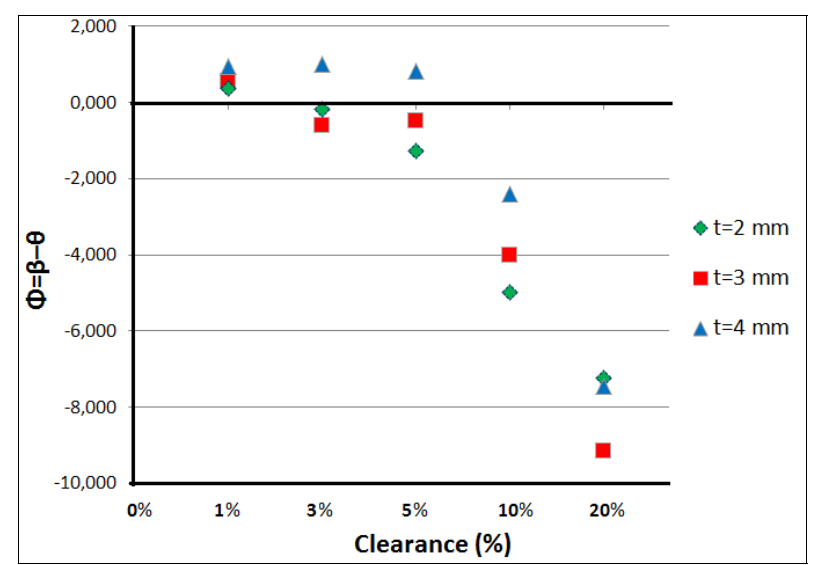

Fig. 8 The difference between real crack propagation angle $(\beta)$ and ideal crack propagation angle $(\theta)$.

propagation angle $(\beta)$ and ideal crack propagation angle $(\theta)$ increased which resulted in low surface quality. $(+)$ and $(-)$ values mean that the real crack propagation followed a direction below ideal crack propagation direction when the value was $(+)$ or real crack propagation followed a direction over ideal crack propagation direction when the value was (-).

In previous researches $[4,15]$, it was suggested that the ideal clearance is between $10 \%$ and $12 \%$ for AISI 304 and $t=1 \mathrm{~mm}$. They also claimed that real crack propagation angle $(\beta)$ remains nearly constant for all clearance values and only ideal crack propagation angle $(\theta)$ changes. Results showed that the increase in the value of $\theta$ is expected because Formula 3 is the representation of a geometrical aspect but $\beta$ also increases with increasing clearance. The only difference is the path that $\beta$ follows (below or top of $\theta$ ) with changing clearance.

\subsection{Indentation Angle}

Indentation angle's $(\alpha)$ change for $t=2 \mathrm{~mm}, t=3$ $\mathrm{mm}$ and $t=4 \mathrm{~mm}$ according to different clearances were given in Fig. 9.

Indentation angle $(\alpha)$ with a small value is important to achieve a good surface quality because it is the value of how the blanked part gets bent from cutting edges through its middle section on the upper portion. In case of too tight clearance $(1 \%)$, indentation angle $(\alpha)$ increases because of the high punch loading. The

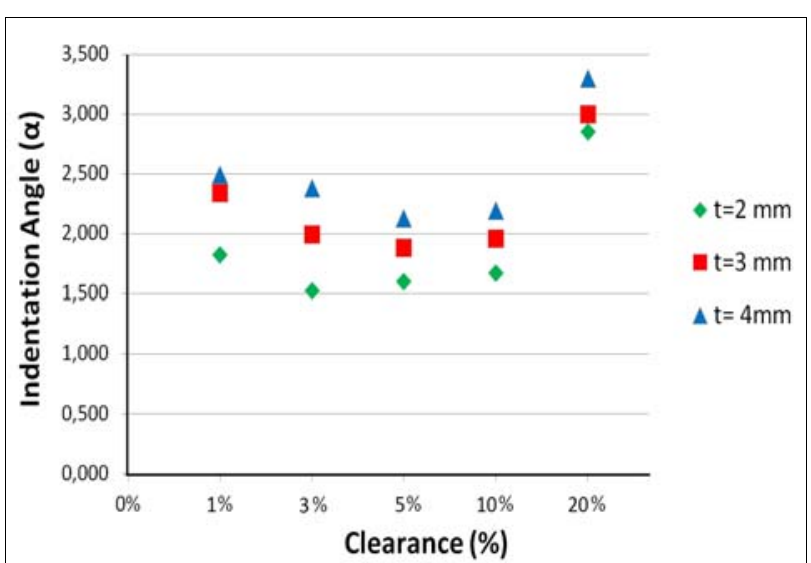

Fig. 9 The variation of indentation angle ( $\alpha)$ according to clearances.

behavior is same with loose clearance ( $10 \%$ and more) because the distance increases between punch and die's cutting edges. In both cases the workpiece bends more.

As can be seen from Fig. 9, indentation angle $(\alpha)$ was lowest at 3\% clearance for $t=2 \mathrm{~mm}$ and lowest at $5 \%$ clearance for $t=3 \mathrm{~mm}$ and $t=4 \mathrm{~mm}$ which are in agreement with results found concerning crack angles and blanking energy.

\subsection{Rollover Depth and Rollover Angle}

Rollover is the bending of the lower portion of the blanked part due to the pulled materials into die cavity. In a blanking process, creation of excessive rollover is not a desired situation. Results showed that there is a connection between indentation angle $(\alpha)$, rollover depth $\left(R_{d}\right)$ and rollover angle $\left(R_{a}\right)$.

Rollover angle is directly affected by rollover depth and indentation angle. Rollover angle increases or decreases with rollover depth's behavior. In case of too tight clearance (1\%), high punching load tries to bend the edge of the blanked part for more rollover. Rollover depth behavior to that exerted force is less than expected because there is a little gap between the punch and the die. However, as a result of more indentation angle due to increased punch load it's still higher than rollover depth created by $3 \%$ and $5 \%$ clearances. For clearances more than $10 \%$, although the punching load is much lower, more material is pulled between the 


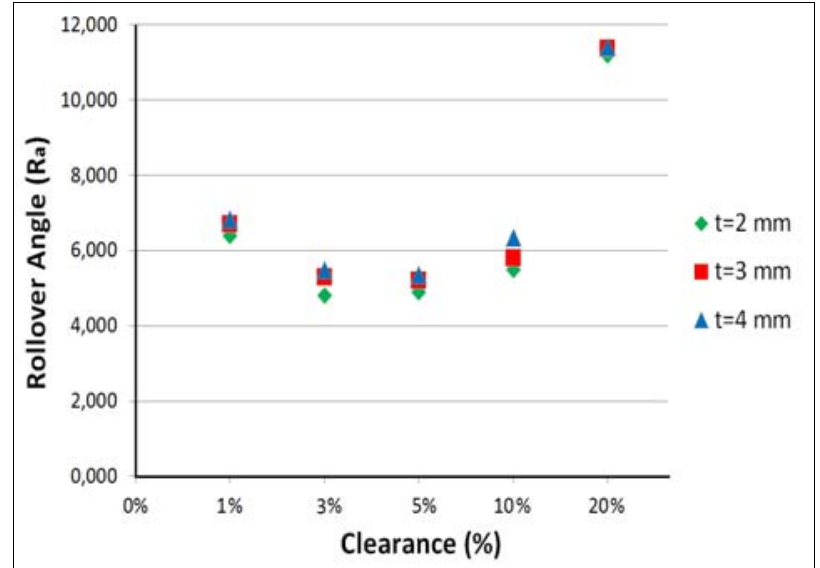

Fig. 10 The change in rollover angle $\left(R_{a}\right)$ with respect to clearances.

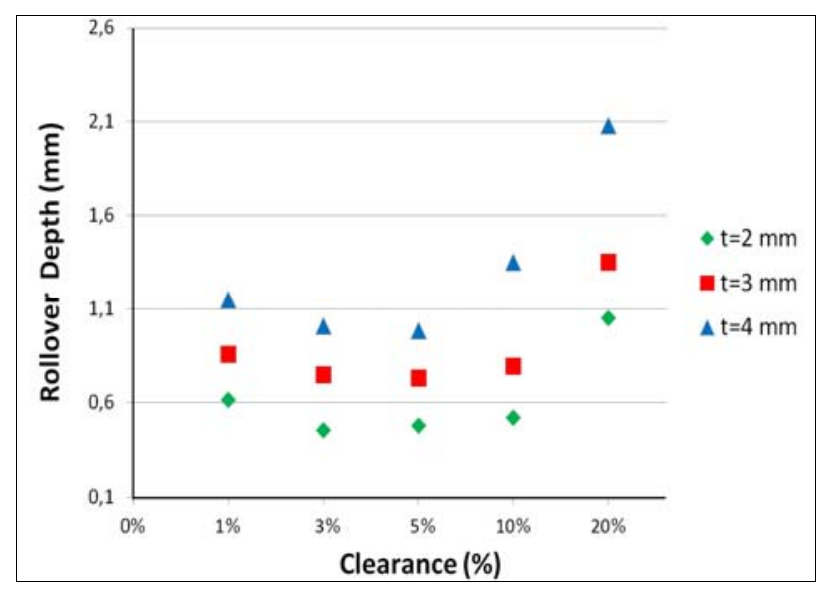

Fig. 11 The change in rollover depth $\left(R_{d}\right)$ with respect to clearances.

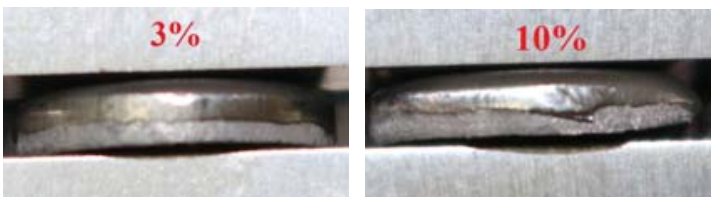

Fig. 12 Blanked surfaces of specimens after experimental study with two clearances ( $c=3 \%$ and $c=10 \%$ ).

punch and the die that results in the increase of rollover depth. This also increases rollover angle.

In Figs. 10 and 11, it can be observed that rollover depth and angle is minimum at $3 \%$ clearance for $t=2$ $\mathrm{mm}$ thickness and minimum at $5 \%$ clearance for $t=3$ $\mathrm{mm}$ and $t=4 \mathrm{~mm}$ thicknesses. These results are in correlation with indentation angle, ideal crack parameters and blanking energy.

The surface differences between $3 \%$ and $10 \%$ clearance after experiments for $t=2 \mathrm{~mm}$ were given in Fig. 12 as an example.

\section{Conclusions}

Blanking of AISI 304 workpieces with three different thicknesses $(t=2 \mathrm{~mm}, t=3 \mathrm{~mm}$ and $t=4 \mathrm{~mm})$ were executed for this study. Five different clearances $(1 \%, 3 \%, 5 \%, 10 \%$ and $20 \%)$ were used to achieve blanks that have $10 \mathrm{~mm}$ diameter. Behaviors of crack propagation angles, indentation angles, rollover angles, rollover depths and blanking energies were observed. Results can be summarized as below;

Clearance has a very important necessity in blanking process. All blanking parameters are dramatically altered with changing clearance.

It was understood that the optimal clearance value where the surface quality is greatest and blanking energy is lowest that creates the ideal cutting condition is dependent on the material kind and thickness. In this study, all parameters became aligned with each other at $3 \%$ clearance for $t=2 \mathrm{~mm}$ and $5 \%$ clearance for $t=3 \mathrm{~mm}$ and $t=4 \mathrm{~mm}$ But, claiming that the optimal clearance is between $3 \%$ and $5 \%$ for all kinds of materials is highly unlikely. It can only be stated that these results are restricted to the material used. However, it's observed that $10 \%$ clearance doesn't have any good result in surface quality and also in blanking energy which some researchers suggested the opposite as a result of their studies with the same material.

Too tight and too loose clearances, also give low surface quality, but as mentioned, it's dependent on the material type and should be investigated.

Blanking load decreases with increasing clearance but that does not mean that usage of high clearances while sacrificing surface quality result in energy saving. High blanking energies because of the increase in stroke length at loose clearances take away all the advantages of using lower blanking loads. Only result is a blank with a ruined surface and spending of more energy if proper clearances are not adjusted.

As the material gets thicker, related process parameters have tendency to increase.

Indentation angle $(\alpha)$, rollover depth $\left(\mathrm{R}_{\mathrm{d}}\right)$ and rollover angle $\left(\mathrm{R}_{\mathrm{a}}\right)$ have a close relationship with each 
other which are also driven by the change in clearance. It can be stated that the ideal cutting condition on a blanked part can be achieved at a clearance where the crack propagations are towards each other, has minimal indentation angle, has minimal rollover depth, has minimal rollover angle and has minimal blanking energy.

\section{References}

[1] Sidhu, K. B., Peshekhodov, I., and Behrens, B. A. 2008. "Numerical Modelling of High Speed Blanking Considering Thermoviscoplastic Effects." In Proceedings of the 3rd International Conference on High Speed Forming, 97-106.

[2] Maiti, S. K., Ambekar, A. A., Singh, U. P., Date, P. P., and Narasimhan, K. 2000. "Assessment of Influence of Some Process Parameters on Sheet Metal Blanking." Journal of Materials Processing Technology 102: 249-56.

[3] Goijaerts, A. M., Stegeman, Y. W., Govaert, L. E., Brokken, D., Brekelmans, W. A. M., and Baaijens, F. P. T. 2000. "Can a New Experimental and Numerical Study Improve Metal Blanking?" Journal of Materials Processing Technology 103: 44-50.

[4] Faura, F., Garcia, A., and Estrems, M. 1998. "Finite Element Analysis of Optimum Clearance in the Blanking Process." Journal of Materials Processing Technology 80-81: 121-5.

[5] Hambli, R., Richir, S., Crubleau, P., and Taravel, B. 2003. "Prediction of Optimum Clearance in Sheet Metal Blanking Processes." International Journal of Advanced Manufacturing Technologies 22: 20-5.

[6] Hambli, R. 2002. "Prediction of Burr Height Formation in Blanking Processes Using Neural Network.” International Journal of Mechanical Sciences 44: 2089-102.

[7] Hambli, R., and Guerin F. 2003. "Application of a Neural Network for Optimum Clearance Prediction in Sheet
Metal Blanking Processes.” Finite Element Analysis in Design 39: 1039-52.

[8] Taupin, E., Breitling, J., Wu, W., and Altan, T. 1996. "Material Fracture and Burr Formation in Blanking Results of FEM Simulations and Comparison with Experiments." Journal of Materials Processing Technology 59: 68-78.

[9] Hatanaka, N., Yamaguchi, K., Takakura, N., and Lizuka, T. 2003. "Simulation of Sheared Edge Formation Process in Blanking of Sheet Metals." Journal of Materials Processing Technology 140: 628-34.

[10] Zhang, J. 2008. "Numerical Study of the Effect of Tool Wear on Burr Formation in Blanking Process." Advanced Materials Research 53-54: 95-100.

[11] Vaz, J. M. and Owen, D. R. J. 2000. "Aspects of Ductile Fracture and Adaptive Mesh Refinement in Damaged Elasto-Plastic Materials." International Journal for Numerical Methods in Engineering 50: 29-54.

[12] Husson, C., Correia, J. P. M., Daridon, L., and Ahzi, S. 2008. "Finite Elements Simulations of Thin Copper Sheets Blanking: Study of Blanking Parameters on Sheared Edge Quality." Journal of Materials Processing Technology 199: 74-83.

[13] Behrens, B., Bouguecha, A., Vucetic, M., Krimm, R., Hasselbusch, T., and Bonk, C. 2014. "Numerical and Experimental Determination of Cut Edge after Blanking of Thin Steel Sheet of DP1000 within Use of Stress Based Damage Model." Procedia Engineering 81: 1096-101.

[14] (2014) ASM Aerospace Specification Metals Inc. website. [Online]. Available: http://asm.matweb.com/

[15] Quazi T. Z., and Shaikh R. S. 2012. "An Overview of Clearance Optimization in Sheet Metal Blanking Process." International Journal of Modern Engineering Research 2: 4547-58.

[16] Gang, F., Pan, Z., and Lulian, L. 2002. "Finite Element Simulation of the Effect of Clearance on the Forming Quality in the Blanking Process." Journal of Materials Processing Technology 122: 249-54. 